\title{
NOTE
}

\section{Determination of lanthanoids and yttrium in JGb2 and JR3 by inductively coupled plasma-mass spectrometry after cation-exchange pretreatment}

\author{
Kyue-Hyung Lee, ${ }^{1}$ Seilchiro Shishido, ${ }^{2}$ Isao Kusachi ${ }^{2}$ and Shoji Motomizu ${ }^{1}$ \\ ${ }^{1}$ Department of Chemistry, Faculty of Science, Okayama University, \\ 3-1-1 Tsushimanaka, Okayama 700-8530, Japan \\ ${ }^{2}$ Department of Earth Sciences, Faculty of Education, Okayama University, \\ 3-1-1 Tsushimanaka, Okayama 700-8530, Japan
}

(Received January 13, 2000; Accepted May 26, 2000)

\begin{abstract}
The lanthanoids (Ln) and yttrium (Y) in rock standard samples issued from the Geological Survey of Japan (GSJ) have been determined by inductively coupled plasma-mass spectrometry (ICP-MS). Sample solutions of two igneous rocks, JGb2 and JR3, with no certified values for Ln and Y were prepared using acid digestion technique, and the $\mathrm{Ln}$ and $\mathrm{Y}$ were separated from other constituents by a cation-exchange column pretreatment. Corrections for polyatomic interference ions were made for the precise and accurate determination of $\mathrm{Ln}$ and $\mathrm{Y}$. The analytical results for $\mathrm{Ln}$ and $\mathrm{Y}$ in $\mathrm{JGb} 2$ obtained by the proposed method were in good agreement with literature values, except for La (22\%), obtained by other ICP-MS coupled with cation-exchange pretreatment. The discrepancy of La abundance was mainly due to the different total blank level.
\end{abstract}

\section{INTRODUCTION}

Information about the contents of rare-earth elements (REEs: lanthanoides, Sc and Y) in environmental samples is very important in geochemical and biochemical studies in order to explain the different process in nature (Panday et al., 1996). In addition, REEs have been used as useful materials for high-technology industries, and therefore the need for accurate trace analysis of REEs in environmental samples has increased (Sen Gupta and Bertrand, 1995). A survey of the data currently available for most environmental standard reference materials (SRMs) from various origins shows the lack of the information on the concentrations of REEs in these materials (Abbey, 1980; Govindaraju, 1984; Jarvis and Jarvis, 1988). This is mainly due to the fact that REEs are difficult to determine because they are a group of closely related elements having very similar physical and chemical properties and their abundances are generally very low.

Inductively coupled plasma-mass spectrometry (ICP-MS) is suitable for determining trace elements in various aqueous samples because of its high sensitivity, rapidity, simplicity, multielemental and isotopic capabilitiy (Lichte et al., 1987; Hwang and Jiang, 1997; Itoh et al., 1999). The trace analysis for REEs by ICP-MS, however, is limited due to mass spectral interferences from molecular ions such as metal oxides or metal hydroxides (Sawatari et al., 1995; Itoh et al., 1998; Zhang et al., 1998). In this work, we adopted the oxide correction method (Lee et al., 2000) to correct the polyatomic interferences from barium oxide ions and REEs oxide ions. Polyatomic interferences from metal oxide ions were corrected based on the results of the experi- 
mentally obtained percentages of the metal oxide formation.

The present method consists of acid digestion of rock samples, matrix elimination and REEs separation with a cation-exchange column, and subsequent analysis by ICP-MS involving metal oxide correction, as well as correction of the signal intensity by an isotopic abundance. The proposed method was applied to the new standard reference rocks with no certified values for $\mathrm{Y}$ and Ln.

\section{EXPERIMENTAL}

\section{Instrumentation}

The ICP-MS instrument used was a Seiko model SPQ $8000 \mathrm{H}$ quadrupole mass spectrometer. Standard operating conditions of ICP-MS system and the data acquisition parameters were summarized in Table 1 . The system was daily checked on sensitivity change and optimized using a solution containing $1 \mu \mathrm{g}^{-1}$ of $\mathrm{Li}, \mathrm{Ba}$ and $\mathrm{Pb}$ to give their maximum sensitivity, followed by the optimization using a $10 \mu \mathrm{g}^{-1}$ solution of Pr, which can give one of the largest rate of oxide formation, to give a minimum ratio of its metal oxide to the metal $\left(\mathrm{MO}^{+} / \mathrm{M}^{+}\right)$before ICP-MS measurement.

\section{Samples}

The following two geological rock standard samples available from Geological Survey of Japan (GSJ, Tsukuba) were examined in this work: JGb2 (Leucogabbro, Tsukuba-san, Ibaraki Prefecture) and JR3 (Peralkaline Rhyolite, Ashizuri, Kochi Prefecture).

\section{Reagents and standard samples}

Multielement standard working solutions which contain fourteen lanthanoids, yttrium and barium were prepared by accurately diluting 1000 $\mathrm{mg} \mathrm{l}^{-1}$ each element solution (Wako Pure Chemicals, Osaka) to give standard solutions of each element concentration range of $0.01-50 \mu \mathrm{g}^{-1}$. Internal standard elements were not added to the working solutions, except for a special case. To match the final acid concentration of the standard
Table 1. Operating parameters of ICP-MS system

\begin{tabular}{ll}
\hline Plasma conditions: & $27.12 \mathrm{MHz}$ \\
Rf frequency & $1.1 \mathrm{~kW}$ \\
ICP radio frequency power & Ar $151 \mathrm{~min}^{-1}$ \\
Plasma gas flow rate & Ar $0.451 \mathrm{~min}^{-1}$ \\
Carrier gas flow rate & Ar $0.501 \mathrm{~min}^{-1}$ \\
Auxiliary gas flow rate & Scott type \\
Spray Chamber & glass concentric type \\
Nebulizer & (Meinhard TR-30-C2) \\
& $1.0 \mathrm{ml} \mathrm{min}{ }^{-1}$ \\
Sample uptake rate & $45000\left({ }^{7} \mathrm{Li}\right)$ \\
Transmission (cps/ppb) & $25000\left({ }^{138} \mathrm{Ba}\right)$ \\
& $22000\left({ }^{208} \mathrm{~Pb}\right)$ \\
& \\
Sampling condition: & $10 \mathrm{~mm} \mathrm{from} \mathrm{load} \mathrm{coil}$ \\
Distance from the load coil & copper $1.1 \mathrm{~mm} \varnothing$ \\
Sampling cone & copper $0.35 \mathrm{~mm} \varnothing$ \\
Skimmer cone & peak hopping mode \\
Data acquisition: & $100 \mathrm{~ms} \mathrm{at} \mathrm{each} \mathrm{m/z}$ \\
Dwell time & 3 points per peak* \\
Data points & 60 \\
No. of scans &
\end{tabular}

*Assuming peak center and $\pm 0.125 u$ from the center.

solutions to sample solutions, $0.1 \mathrm{M}$ nitric acid was used as a diluent for preparing the standard samples. Ultrapure water (18.2 $\mathrm{M} \Omega \mathrm{cm}$ resistivity) was prepared by Milli-Q Labo (Nihon Millipore, Tokyo). Ultrapure grade nitric acid (60\%, Kanto Chemicals) was diluted with ultrapure water to give a $0.1 \mathrm{M}$ solution. For the preparation of all solutions, such as standard solutions for calibration, rock sample solutions, oxide monitoring solutions and artificial mixed standard solutions, the $0.1 \mathrm{M}$ nitric acid solution was used. All dilution procedures were performed by weight. The use of glass labwares was avoided, and plastic labwares such as poly(tetrafluoroethylene) (PTFE), polyethylene and polypropylene were used after being treated by soaking for a week in $1 \mathrm{M} \mathrm{HNO}_{3}$ and then rinsing them by ultrapure water. All acids $\left(\mathrm{HF}, \mathrm{H}_{2} \mathrm{SO}_{4}, \mathrm{HCl}, \mathrm{HNO}_{3}\right)$ used for the cationexchange column pretreatment were of an analytical reagent grade.

\section{Acid digestion of rock standard samples}

A powdered rock sample of $100 \mathrm{mg}$ was weighed in a PTFE vial (PFA jar, a volume of 7 ml; Masuda Rika, Osaka, Japan) with a screw cap, 
being wetted with $1 \mathrm{ml}$ of conc. $\mathrm{HNO}_{3}$ and $3 \mathrm{ml}$ of conc. HF. Then, the vial was sealed with the cap, and was heated on a sand bath at $100^{\circ} \mathrm{C}$ in a draft chamber for $24 \mathrm{hrs}$. After the mixture being almost dissolved, it was heated several times at an interval of 1 minute by using a microwave oven to obtain a clear solution. Then, the vial was opened and the solution was evaporated to dryness on a sand bath at $140^{\circ} \mathrm{C}$. After $0.5 \mathrm{ml}$ (about 15 drops) of conc. perchloric acid was added dropwise to the residue, the hydrofluoric acid produced was eliminated on a sand bath at $200^{\circ} \mathrm{C}$. The residue was redissolved in $5 \mathrm{ml}$ of $6 \mathrm{M} \mathrm{HCl}$, and the solution was again evaporated to dryness; in this step, all metals were converted to metal chlorides. The residue thus obtained was dissolved in $14 \mathrm{ml}$ of a mixed acid (31.5 $\mathrm{g}$ of oxalic acid in $500 \mathrm{ml}$ of $2 \mathrm{M} \mathrm{HNO}_{3}$ ) and warmed on the water bath in order to dissolve the iron precipitates.

\section{Column separation of REEs from other metals}

For an accurate ICP-MS measurement of REEs at low concentrations, usually it is necessary to separate the target elements from coexisting elements at extremely high concentrations in sample solutions and to enrich them. When accurate and precise analytical data are required for such samples as certified reference materials, ICP-MS coupled with the pretreatment with column separation techniques will be more desired (Hirata et al., 1988; Barrat et al., 1996; Pin and Joannon, 1997). The ICP-MS coupled with the pretreatment can eliminate most of the disadvantages accompanying with ICP-MS measurements. In our previous work (Lee et al., 2000), the authors could determine the REEs contents in the eleven GSJ reference materials (igneous rock series) by ICP-MS after cation-exchange column pretreatment, and the more reliable analytical data could be obtained using oxide correction method. The accuracy and precision of the method was within $\pm 10 \%$ and better than $3.5 \%$ RSD (relative standard deviations), respectively.

An AG-50WX-12 Dowex resin (200 400 mesh; Bio-Rad, Richmond, CA), strong cation exchanger, was used for the separation of $\mathrm{Y}$ and
REEs from other constituents. Eight milliliters of the cation exchanger resin (suspended in $\mathrm{H}_{2} \mathrm{O}$ ) was transferred into a $13 \mathrm{~mm}$ i.d. $\times 120 \mathrm{~mm}$ plastic column (Muromachi Chemicals, Japan). After the resin being washed with $20 \mathrm{ml}$ of $8 \mathrm{M} \mathrm{HNO}_{3}$ at a flow rate of $2 \mathrm{ml} \mathrm{min}^{-1}$ and $30 \mathrm{ml}$ of $\mathrm{H}_{2} \mathrm{O}$ at a flow rate of $2 \mathrm{ml} \mathrm{min}^{-1}$, it was preconditioned by flowing $20 \mathrm{ml}$ of $2 \mathrm{M} \mathrm{HNO}_{3}$ at a flow rate of $2 \mathrm{ml}$ $\mathrm{min}^{-1}$. The rock sample solution $(14 \mathrm{ml})$ prepared according to the procedures described in the section of the acid digestion was cautiously added to the cation-exchange column and was flowed at a flow rate of $2 \mathrm{ml} \mathrm{min}^{-1}$. After all the sample solution was transferred to the column, $75 \mathrm{ml}$ of $2 \mathrm{M}$ $\mathrm{HNO}_{3}$ was added to the column and was flowed at a flow rate of $2 \mathrm{ml} \mathrm{min}^{-1}$ for eliminating almost all of such major components as $\mathrm{Fe}, \mathrm{Al}$, alkali metals, alkaline earth metals and transition metals present in the rock samples. After the metal ions except for the REEs being eluted from the column, the REEs were eluted with $50 \mathrm{ml}$ of $6 \mathrm{M}$ $\mathrm{HNO}_{3}$ at a flow rate of $2 \mathrm{ml} \mathrm{min}{ }^{-1}$. The REEs fraction thus obtained was evaporated to dryness, the residue being dissolved in $0.1 \mathrm{M} \mathrm{HNO}_{3}$ to give a $25 \mathrm{ml}$ stock solution. Again this solution was 25fold diluted with $0.1 \mathrm{M} \mathrm{HNO}_{3}$ solution to be measured by ICP-MS.

\section{Analytical procedures}

The order of ICP-MS measurements was as follows: measuring a blank solution $\left(0.1 \mathrm{M} \mathrm{HNO}_{3}\right)$, the series of the multielement standard solutions, the monitoring solutions for metal oxide corrections, and the rock sample solutions. Five kinds of the monitoring solutions ((a) $\mathrm{Ba}+\mathrm{Pr}+\mathrm{Tb}$, (b) $\mathrm{Ce}$, (c) $\mathrm{Nd}$, (d) Sm and (e) Gd) contain $10 \mu \mathrm{g} \mathrm{l}^{-1}$ of each element. Total measuring time for a measurement was about $3 \mathrm{~min}$, including $2 \mathrm{~min}$ for ICPMS measurement of 15 elements and one minute for signal drop down to the background by nebulizing ultrapure water and $0.1 \mathrm{M} \mathrm{HNO}_{3}$ solution. The ratios of $\mathrm{MO}^{+} / \mathrm{M}^{+}$of barium and each rare earth were obtained as an average value by measuring the five monitoring solutions, and the true ion counts of the analyte isotope were obtained by subtracting the ion counts of the inter- 
fering metal oxide from the apparent ion counts of the analyte isotopes. As a result, corrected calibration curves for all REEs were obtained, and used for the determination of concentrations of REEs in rocks.

\section{Correction method for metal oxide interferences}

Since the REEs are a group of strong oxide formers, the oxides of light REEs (LREEs) may cause significant interferences with the counts of isotopes of heavy REEs (HREEs). Hydroxide correction was not carried out in the present method because the interferences of $\mathrm{MOH}^{+}$were negligibly small (less than 1/10) compared with those of the $\mathrm{MO}^{+}$. Although the formation of such molecular ions can be minimized by the optimization of the instrumental parameters, such as radio-frequency power, distance from the load coil to interface, nebulizer flow rate, design of cones and ion lens setting, it is impossible to eliminate it completely (Horlick et al., 1985; Gray, 1986; Vaughan and Horlick, 1986; Date et al., 1987; Gray and Williams, 1987; Longerich et al., 1987).

In our previous work (Lee et al., 2000), the authors demonstrated the ratios of $\mathrm{MO}^{+} / \mathrm{M}^{+}$for barium and possible rare earth elements using three kinds of monitoring solutions containing 1 , 10 and $100 \mu \mathrm{g}^{-1}$ of such metal ions. The values of $\mathrm{MO}^{+} / \mathrm{M}^{+}$for all metals examined were almost constant over the wide ranges of $10^{2}$ order. This result indicates that the intensities of interfering oxide ions are proportional to the concentration

Table 2. Isotopes selected for analysis, total blanks, limits of detection (LOD) and main isobaric interferences

\begin{tabular}{|c|c|c|c|c|c|}
\hline Element & $\mathrm{m} / \mathrm{z}$ & Total blank (ng)*1 & $\operatorname{LOD}\left(\operatorname{ng~}^{-1}\right)^{* 2}$ & Isobaric interferences ${ }^{* 3}$ & Monitoring isotopes ${ }^{* 7}$ \\
\hline $\mathrm{Y}$ & 89 & 0.25 & 0.09 & & \\
\hline $\mathrm{Ba}$ & 138 & & & ${ }^{138} \mathrm{La}^{+}$and ${ }^{138} \mathrm{Ce}^{+} * 4$ & ${ }^{138} \mathrm{La}^{+}$and ${ }^{138} \mathrm{Ce}^{+}$ \\
\hline $\mathrm{La}$ & 139 & 0.28 & 0.13 & & \\
\hline $\mathrm{Ce}$ & 140 & 0.83 & 0.14 & & \\
\hline $\operatorname{Pr}$ & 141 & 0.12 & 0.07 & & \\
\hline $\mathrm{Nd}$ & 142 & 0.22 & 0.27 & ${ }^{142} \mathrm{Ce}^{+}$ & ${ }^{142} \mathrm{Ce}^{+}$ \\
\hline $\mathrm{Nd}$ & 146 & & 0.55 & ${ }^{130} \mathrm{BaO}^{+} * 5$ & \\
\hline $\mathrm{Sm}$ & 147 & 0.08 & 0.33 & & \\
\hline $\mathrm{Sm}$ & 152 & & 0.24 & ${ }^{136} \mathrm{BaO}^{+}$ & ${ }^{138} \mathrm{Ba}^{+}$ \\
\hline $\mathrm{Eu}$ & 153 & 0.05 & 0.22 & ${ }^{137} \mathrm{BaO}^{+}$ & ${ }^{138} \mathrm{Ba}^{+}$ \\
\hline $\mathrm{Gd}$ & 157 & 0.09 & 0.60 & ${ }^{141} \mathrm{PrO}^{+}$ & ${ }^{141} \mathrm{Pr}^{+}$ \\
\hline $\mathrm{Gd}$ & 158 & & 0.48 & ${ }^{142} \mathrm{CeO}^{+}$and ${ }^{142} \mathrm{NdO}^{+}$ & ${ }^{140} \mathrm{Ce}^{+}$and ${ }^{146} \mathrm{Nd}^{+}$ \\
\hline $\mathrm{Tb}$ & 159 & 0.02 & 0.07 & ${ }^{143} \mathrm{NdO}^{+}$ & ${ }^{146} \mathrm{Nd}^{+}$ \\
\hline Dy & 164 & 0.07 & 0.09 & ${ }^{149} \mathrm{NdO}^{+}$and ${ }^{149} \mathrm{SmO}^{+}$ & ${ }^{146} \mathrm{Nd}^{+}$and ${ }^{147} \mathrm{Sm}^{+}$ \\
\hline Ho & 165 & 0.02 & 0.07 & ${ }^{149} \mathrm{SmO}^{+}$ & ${ }^{147} \mathrm{Sm}^{+}$ \\
\hline $\mathrm{Er}$ & 166 & 0.03 & 0.13 & ${ }^{150} \mathrm{NdO}^{+}$and ${ }^{150} \mathrm{SmO}^{+}$ & ${ }^{146} \mathrm{Nd}^{+}$and ${ }^{147} \mathrm{Sm}^{+}$ \\
\hline $\mathrm{Tm}$ & 169 & 0.01 & 0.05 & ${ }^{153} \mathrm{EuO}^{+} * 6$ & ${ }^{153} \mathrm{Eu}^{+}$ \\
\hline $\mathrm{Yb}$ & 174 & 0.01 & 0.09 & ${ }^{158} \mathrm{GdO}^{+}$and ${ }^{158} \mathrm{DyO}^{+}$ & ${ }^{157} \mathrm{Gd}^{+}$and ${ }^{164} \mathrm{Dy}^{+}$ \\
\hline $\mathrm{Lu}$ & 175 & 0.01 & 0.08 & ${ }^{159} \mathrm{TbO}^{+}$ & ${ }^{159} \mathrm{~Tb}^{+}$ \\
\hline
\end{tabular}

*I Total processing blanks $(n=2)$.

$*^{2}$ Limits of detection, corresponding to $3 \sigma$, where $\sigma$ is standard deviation of a blank solution $(0.1 M$ nitric acid, $n=10)$.

*3 This column represents the oxides and isotopes, which are used for isobaric corrections of analytes to obtain their true ion counts. Other interfering oxide species may be formed, but their interferences can be considered to be negligible.

${ }^{* 4}{ }^{138} \mathrm{Ba}^{+}$was isotopically interfered from the ion counts of both ${ }^{138} \mathrm{La}^{+}$(natural abundance $0.09 \%$ ) and ${ }^{138} \mathrm{Ce}^{+}$(natural abundance $0.25 \%$ ), but these contributions were negligibly small and can be ignored.

${ }^{* 5}{ }^{146} \mathrm{Nd}^{+}$was interfered from ${ }^{130} \mathrm{BaO}^{+}$, but this contribution could be ignored because of the very low natural abundance of ${ }^{130} \mathrm{Ba}(0.106 \%)$.

${ }^{* 6}{ }^{169} \mathrm{Tm}^{+}$was interfered from ${ }^{153} \mathrm{EuO}^{+}$, but this contribution could be ignored because the natural abundance ratio of Eu/Tm is generally small and oxide ratio $\left({ }^{153} \mathrm{EuO}^{+153} \mathrm{Eu}^{+}\right)$is low (0.062).

${ }^{* 7}$ These isotopes were monitored and their monitored ion counts were used to correct the isobaric interferences. 
of the monitoring elements (isotopes). Thus we made a simple equations to correct for metal oxide effect on the basis of an algebraic principle.

The analyte isotopes and the corresponding monitoring isotopes used for correcting the effect of metal oxide ions are summarized in Table 2, together with the corresponding instrumental limits of detection (LODs) and total blanks. The in- strumental LODs for all elements were sub-ppt

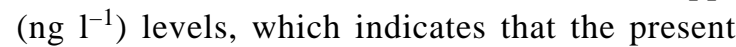
ICP-MS system is sensitive enough for determining REEs in the rock samples, even after large dilution. The total blank values for light REEs (Y, $\mathrm{La}, \mathrm{Ce}, \mathrm{Pr}$ and $\mathrm{Nd}$ ) were little higher than middle or heavy REEs ( $\mathrm{Sm} \sim \mathrm{Lu})$ by the degree of one order. However, higher blanks of LREEs were not

Table 3. Isobaric interferences from metal oxides in ICP-MS and formation ratios of metal oxide ions experimentally obtained in this work

\begin{tabular}{cccc}
\hline Interfered isotopes & Interfering species $\left(\mathrm{MO}^{+}\right)$ & Isotopes $\left(\mathrm{M}^{+}\right)$for oxide monitoring & Ratio $(\%)$ of $\mathrm{MO}^{+} / \mathrm{M}^{+}$ \\
\hline${ }^{152} \mathrm{Sm}^{+}$ & ${ }^{136} \mathrm{BaO}^{+}$ & ${ }^{138} \mathrm{Ba}^{+}$ & 0.043 \\
${ }^{153} \mathrm{Eu}^{+}$ & ${ }^{137} \mathrm{BaO}^{+}$ & ${ }^{138} \mathrm{Ba}^{+}$ & 0.051 \\
${ }^{157} \mathrm{Gd}^{+}$ & ${ }^{141} \mathrm{PrO}^{+}$ & ${ }^{141} \mathrm{Pr}^{+}$ & 6.3 \\
${ }^{158} \mathrm{Gd}^{+}$ & ${ }^{142} \mathrm{NdO}^{+}$ & ${ }^{146} \mathrm{Nd}^{+}$ & 6.7 \\
${ }^{158} \mathrm{Gd}^{+}$ & ${ }^{142} \mathrm{CeO}^{+}$ & ${ }^{140} \mathrm{Ce}^{+}$ & 1.4 \\
${ }^{159} \mathrm{~Tb}^{+}$ & ${ }^{143} \mathrm{NdO}^{+}$ & ${ }^{146} \mathrm{Nd}^{+}$ & 3.0 \\
${ }^{164} \mathrm{Dy}^{+}$ & ${ }^{146} \mathrm{Nd}^{+}$ & 1.5 \\
${ }^{164} \mathrm{NdO}^{+}$ & ${ }^{148} \mathrm{SmO}^{+}$ & ${ }^{147} \mathrm{Sm}^{+}$ & 0.48 \\
${ }^{165} \mathrm{Ho}^{+}$ & ${ }^{149} \mathrm{SmO}^{+}$ & ${ }^{147} \mathrm{Sm}^{+}$ & 0.59 \\
${ }^{166} \mathrm{Er}^{+}$ & ${ }^{150} \mathrm{NdO}^{+}$ & ${ }^{146} \mathrm{Nd}^{+}$ & 1.5 \\
${ }^{166} \mathrm{Er}^{+}$ & ${ }^{157} \mathrm{Sm}^{+}$ & 0.32 \\
${ }^{169} \mathrm{SmO}^{+}$ & ${ }^{153} \mathrm{Eu}^{+}$ & 0.062 \\
${ }^{174} \mathrm{Yb}^{+}$ & ${ }^{153} \mathrm{EuO}^{+}$ & ${ }^{164} \mathrm{Dy}^{+}$ & 0.004 \\
${ }^{174} \mathrm{Yb}^{+}$ & ${ }^{158} \mathrm{DyO}^{+}$ & ${ }^{157} \mathrm{Gd}^{+}$ & 4.5 \\
${ }^{175} \mathrm{Lu}^{+}$ & ${ }^{158} \mathrm{GdO}^{+}$ & ${ }^{159} \mathrm{~Tb}^{+}$ & 2.1 \\
\hline
\end{tabular}

Table 4. Isobaric oxide correction method for REEs used in this study

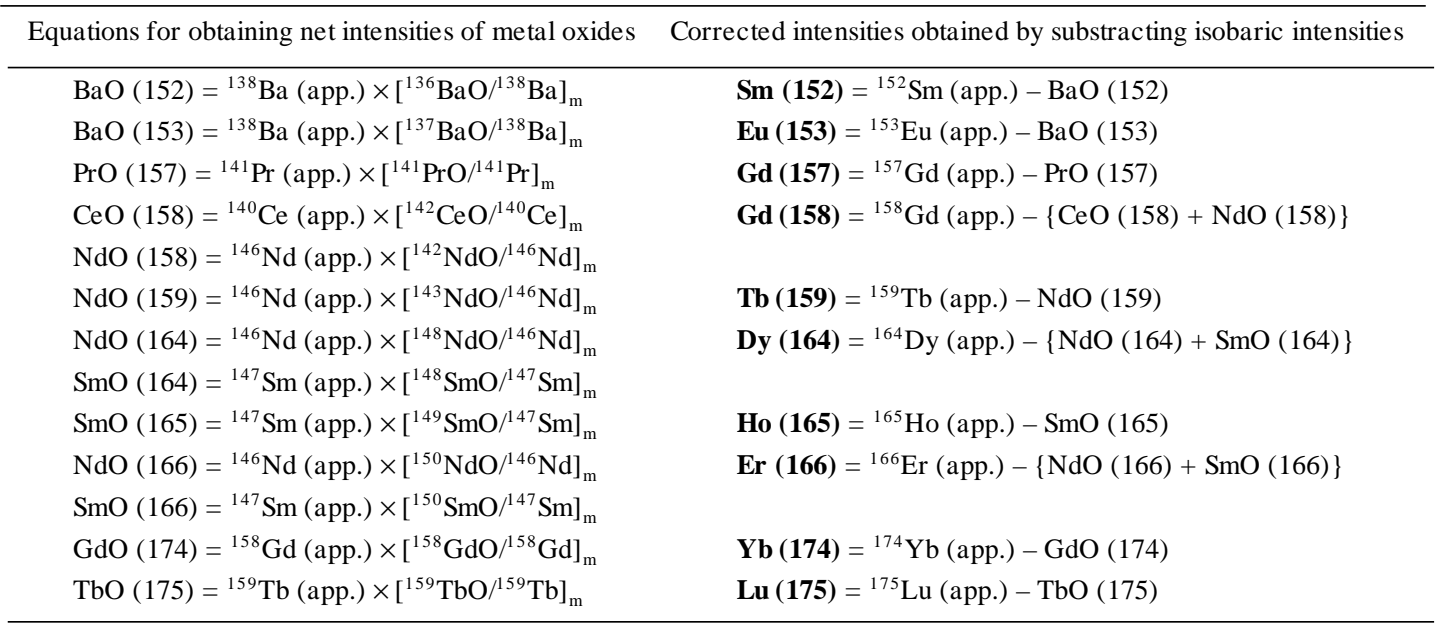

(app.) means apparent peak intensity of a metal ion.

[]$_{m}$ means $\mathrm{MO}^{+} / \mathrm{M}^{+}$ratio, which can be calculated by using the results obtained for monitoring standard solutions (see Table 3).

The bold values show the corrected intensities. 
affected on determining the abundances in rock samples tested in this study. The isotopes for the determination of the REEs were firstly selected: the natural abundance was the highest of all the corresponding isotopes, secondly the interferences from isobaric overlaps were less, and last the corrections of metal oxides were simple and necessitated less steps of corrections. It can be seen that four of the REEs, La, Ce, Pr and Y, could be determined without any metal oxide correction. Pairs of isotopes were selected for the determination of $\mathrm{Nd}, \mathrm{Sm}$ and $\mathrm{Gd}$, to compare and verify their analytical results obtained by using different correction procedures.

The ratios of $\mathrm{MO}^{+} / \mathrm{M}^{+}$for barium and possible rare-earth elements using $10 \mu \mathrm{g} \mathrm{l}^{-1}$ of monitoring solutions were shown in Table 3 , and the equations for calculating the contribution of metal oxides to analyte ions examined in this work were summarized in Table 4.

The calibration curves of all analyte ions, whose counts were corrected by the oxide correction method, showed good linearity (correlation coefficient $\geqq 0.999$ ) within their concentration ranges from 0.01 to $50 \mu \mathrm{g} 1^{-1}$.

\section{RESULTS AND DISCUSSION}

Validation of non-internal standardization method

Many workers (Doherty, 1989; Imai, 1990; Vaughan and Horlick, 1990; Stroh et al., 1995;
Shinotsuka et al., 1996; Tsuji et al., 1998) have used internal standard elements to compensate for the signal drift or sensitivity change in determining REEs by ICP-MS. The addition of internal standard elements, however, is just for the signal compensation of each isotope, not for the polyatomic interference. The present authors showed that in case of measuring the pretreated and clean rock samples non-internal standardization method could give least signal drift within $\pm 2 \%$ and accurate analytical results even when ICP-MS measurement was carried out over the period of $6 \mathrm{~h}$ (Lee et al., 2000).

In the present study, the comparison of the accuracy and precision between non-internal standardization method (NISM) and internal standardization method (ISM) was performed. In order to show the validity of the present study, a JB-1 rock reference material issued from GSJ (Basalt, Sasebo, Nagasaki Prefecture) was analyzed by the two methods, that is ISM and NISM. The two methods were carried out with the same oxide correction procedures. In ISM, indium $\left(20 \mu \mathrm{g} \mathrm{l}^{-1}\right)$ was spiked as an internal standard for normalizing REEs in both standard solutions and rock sample solutions. The spiked samples (sample 1 and sample 2) were determined by ISM. The unspiked samples (sample 3 and sample 4) were determined by NISM. These four independent samples were pretreated with independent separation procedure. The diagram of deviations from certified values
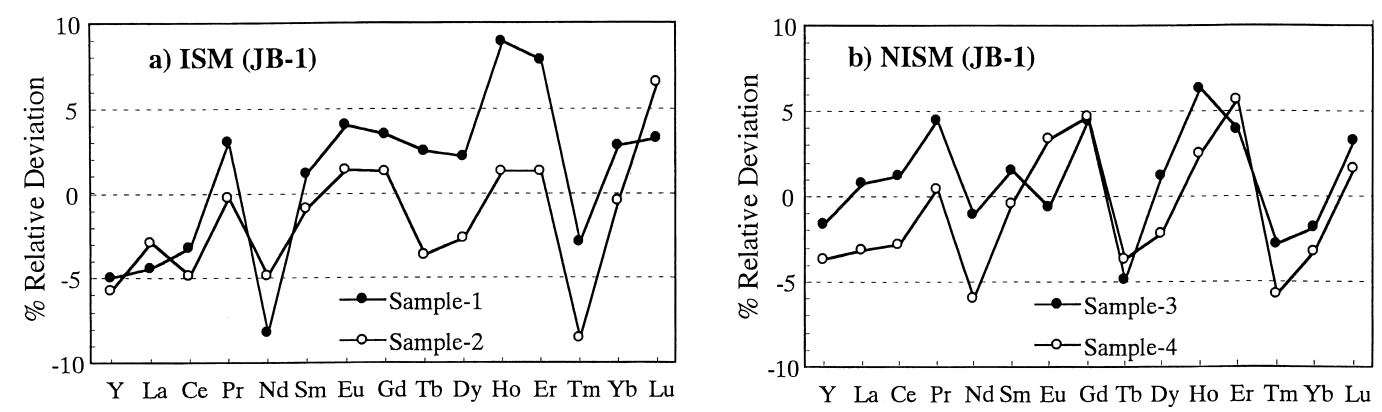

Fig. 1. Comparison of analytical results of ISM with those of NISM for JB-1 rock standard sample. Sample 1, 2 and sample 3, 4 are duplicate. a) ISM means internal standardization method, and these results were obtained by the solutions spiked with indium $\left(20 \mathrm{ng} \mathrm{ml}^{-1}\right)$. b) NISM means non-internal standardization method, and these values were obtained by using the solutions in which no internal standard was spiked. The vertical axis represents relative deviations from certified values (Imai, 1990). 
for Ln and Y obtained by different two methods were plotted in Fig. 1. The results obtained by the different two methods showed good coincidence with each other, and they are in very good agreement with certified values. The relative deviations for all REEs between the results of NISM and certified values were less than 5\%. There was no remarkable difference on accuracy and precision between two methods. These results suggest that ISM is not always necessary to determine REEs in case of pretreated and clean sample. It should be stressed here that the errors caused by the metal oxides were more serious than the errors caused by NISM on determining REEs in matrix-free solution. For outstanding example, ${ }^{158} \mathrm{Gd}^{+}$value without metal oxide correction and with the compensation by the internal standard was deviated by $60 \%$ from the JB- 1 certified value, whereas ${ }^{158} \mathrm{Gd}^{+}$value with metal oxide correction and without the compensation by the internal standard was deviated by less than $5 \%$ from the certified value.

\section{Recovery of REEs in the column pretreatment}

In our previous study (Lee et al., 2000), the artificial standard solutions, which contain REE

Table 5. Recoveries of REEs with ion exchange column pretreatment

\begin{tabular}{cc}
\hline Element & Recovery $(\%)^{*}$ \\
\hline $\mathrm{Y}$ & $101 \pm 2.2$ \\
$\mathrm{La}$ & $99.0 \pm 1.7$ \\
$\mathrm{Ce}$ & $98.9 \pm 3.0$ \\
$\mathrm{Pr}$ & $100 \pm 2.6$ \\
$\mathrm{Nd}$ & $98.8 \pm 2.9$ \\
$\mathrm{Sm}$ & $98.0 \pm 1.8$ \\
$\mathrm{Eu}$ & $98.1 \pm 2.7$ \\
$\mathrm{Gd}$ & $97.6 \pm 3.4$ \\
$\mathrm{~Tb}$ & $97.9 \pm 3.2$ \\
$\mathrm{Dy}$ & $98.7 \pm 2.5$ \\
$\mathrm{Ho}$ & $99.5 \pm 2.4$ \\
$\mathrm{Er}$ & $102 \pm 2.8$ \\
$\mathrm{Tm}$ & $99.1 \pm 2.1$ \\
$\mathrm{Yb}$ & $101 \pm 1.8$ \\
$\mathrm{Lu}$ & $99.2 \pm 1.6$ \\
\hline
\end{tabular}

*The figures show average values of recovery $(n=12)$ obtained from artificial rock samples which contents of REEs are similar to those of JB1, JG2, JGb1 and JR2.

The figures with \pm show standard deviations. compositions as nearly the same GSJ rock standard samples, such as JB-1, JG2, JGb-1 and JR-1, were examined to evaluate the recoveries of REEs in the cation-exchange column pretreatment. As a result, recovery of $\mathrm{Y}$ and all $\mathrm{Ln}$ in these artificial samples was $100 \pm 4 \%$. The recoveries of REEs are listed in Table 5 . The reproducibility $(n=5)$ was better than $3 \%$ RSD. From these results, the recovery of REEs from column pretreatment will be very quantitative.

\section{Validation of oxide correction method}

Two artificial rock samples (ART (JGb1) and ART (JR2)), which contain Y, Ba and lanthanoids at almost the same proportion as JGb1 and JR2, were prepared. These solutions did not contain other matrix elements possibly existing in rock samples, because in the column pretreatment most major elements in rock samples can be removed. The analytical data for two kinds of the solutions were obtained by using the oxide correction method. Table 6 shows the comparison of the corrected analysis data with the uncorrected data. The results show that the corrected data are in good agreement with the expected values (prepared concentrations), while all uncorrected values of ${ }^{142} \mathrm{Nd}^{+},{ }^{152} \mathrm{Sm}^{+},{ }^{153} \mathrm{Eu}^{+},{ }^{157} \mathrm{Gd}^{+},{ }^{158} \mathrm{Gd}^{+},{ }^{159} \mathrm{~Tb}^{+}$, ${ }^{164} \mathrm{Dy}^{+},{ }^{166} \mathrm{Er}^{+},{ }^{174} \mathrm{Yb}^{+}$and ${ }^{175} \mathrm{Lu}^{+}$show positive errors, compared with the expected values.

In the proposed column procedures, Ba was not separated completely from the REEs, and showed somewhat similar elution behavior to the REEs. Therefore, barium oxide can produce positive errors to ${ }^{146} \mathrm{Nd}^{+},{ }^{150} \mathrm{Nd}^{+},{ }^{150} \mathrm{Sm}^{+},{ }^{152} \mathrm{Gd}^{+}$, ${ }^{152} \mathrm{Sm}^{+},{ }^{151} \mathrm{Eu}^{+},{ }^{153} \mathrm{Eu}^{+}$and ${ }^{154} \mathrm{Gd}^{+}$, although the ratio of $\mathrm{BaO}^{+} / \mathrm{Ba}^{+}$was very low. The polyatomic interference of $\mathrm{BaO}^{+}$on these isotopes was substantial; it was about $0.05 \%$ in ${ }^{152} \mathrm{Sm}^{+},{ }^{151} \mathrm{Eu}^{+}$and ${ }^{153} \mathrm{Eu}^{+}$. The polyatomic interference of $\mathrm{BaO}^{+}$on other species was too small to be neglected. The results obtained for the pairs of isotopes, such as ${ }^{142} \mathrm{Nd}^{+}$and ${ }^{146} \mathrm{Nd}^{+},{ }^{147} \mathrm{Sm}^{+}$and ${ }^{152} \mathrm{Sm}^{+}$, and ${ }^{157} \mathrm{Gd}^{+}$ and ${ }^{158} \mathrm{Gd}^{+}$showed excellent agreement with each other. These results assure us that the oxide correction method is valid and essential to accurate determination of lanthanoids. 


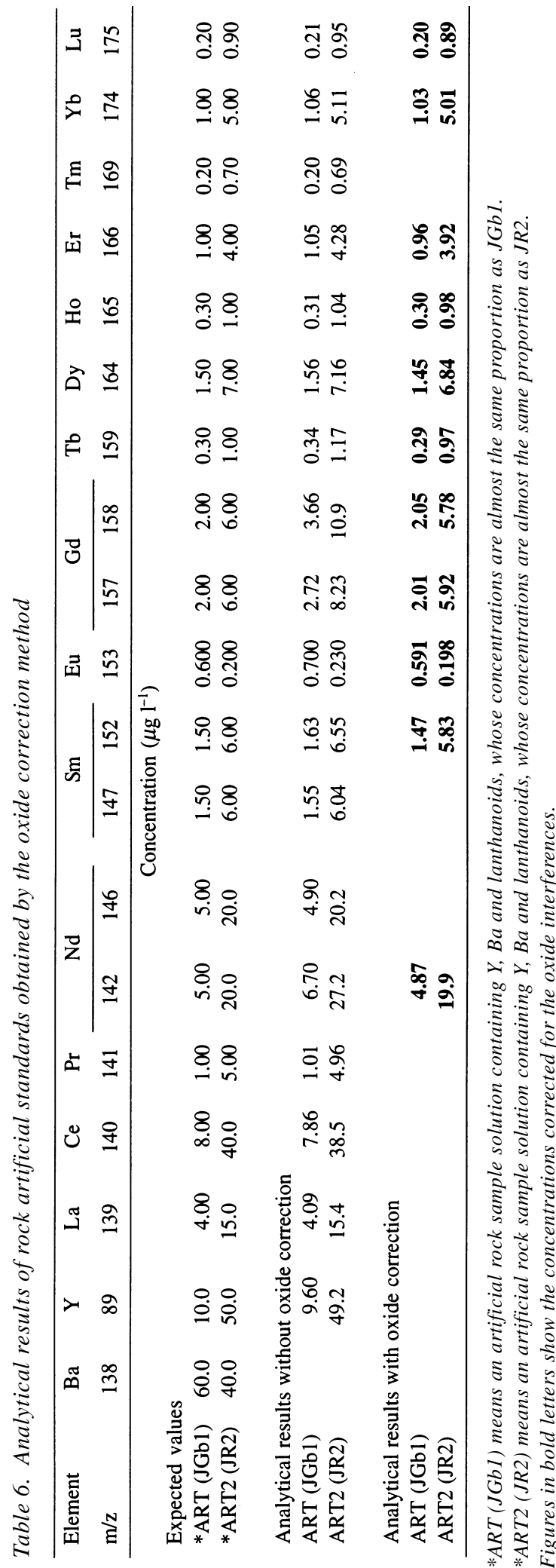

Analysis of rock standard samples

The analytical results of $\mathrm{Ln}$ and $\mathrm{Y}$ in the two rock standard samples obtained by the proposed method are summarized in Table 7. Literature values (Pin and Joannon, 1997) for REEs in JGb2 are also included in Table 7 for the comparison of the present REEs data and the methodology differences. The literature values were obtained by ICP-MS fitted with a low flow, micro-concentric nebulizer after group separation using cation-exchange chromatography which was based on the sequential use of $\mathrm{HCl}$ and $\mathrm{HNO}_{3}$ as eluting agents. Internal standardization method using linear interpolation between ${ }^{115} \mathrm{In}$ and ${ }^{185} \mathrm{Re}$ was used to correct for instrumental drift. For determining REEs in JGb2, oxide correction was not done but selected less interfered isotopes sacrificing sensitivity. The overall repeatability for three replicates was in the range of $2 \%$ to $5 \%$.

Rock reference material was treated in duplicate with duplicate columns, and the duplicate final solutions were measured in five replicates by ICP-MS. The RSD values obtained by five replicate measurements for each sample were less than $3 \%$. The difference between duplicate column pretreatment was very small, which indicates that the column pretreatment and the ICP-MS measurement are thought to be very reproducible and reliable. Our results for JGb2, except for the results of $\mathrm{La}$ and Er, are in good agreement with the literature values. The deviations of our results from the literature values were within $\pm 10 \%$, except for La $(21.8 \%)$ and $\operatorname{Er}(11.1 \%)$. The first possibility of deviation of La abundance can be produced considering the different total blank level between the literature $(1.2 \mathrm{ng})$ and the present study (0.13 $\mathrm{ng})$. Secondly, the La discrepancy may be due to memory effect or contamination from the microconcentric nebulizer used in the literature.

The REEs abundances in geochemical samples are often discussed in the manner of their relative abundances normalized to those in chondrites. In this study, the analytical data of REEs were normalized to the CI chondrite values (Anders and Grevesse, 1989), and the normalized values were plotted as in Fig. 2. The normalization of the REEs 
Table 7. Analytical results of GSJ rock reference materials by the proposed ICP-MS method

\begin{tabular}{|c|c|c|c|c|c|}
\hline \multirow[t]{3}{*}{ Element } & \multicolumn{5}{|c|}{ Concentration $\left(\mu \mathrm{g} \mathrm{g}^{-1}\right)$} \\
\hline & \multicolumn{3}{|c|}{$\mathrm{JGb} 2$} & \multicolumn{2}{|c|}{ JR-3 } \\
\hline & Sample $1 * 1$ & Sample $2 * 1$ & Ref. $*^{2}$ & Sample $1 * 1$ & Sample $2 * 1$ \\
\hline $\mathrm{Y}$ & $3.35 \pm 0.080$ & $3.38 \pm 0.060$ & - & $43.4 \pm 0.23$ & $43.6 \pm 0.22$ \\
\hline $\mathrm{La}$ & $1.15 \pm 0.025$ & $1.14 \pm 0.022$ & $1.47 \pm 0.046$ & $154 \pm 0.1$ & $154 \pm 0.1$ \\
\hline $\mathrm{Ce}$ & $3.15 \pm 0.05$ & $3.22 \pm 0.06$ & $3.16 \pm 0.005$ & $257 \pm 0.7$ & $254 \pm 0.7$ \\
\hline $\operatorname{Pr}$ & $0.406 \pm 0.005$ & $0.411 \pm 0.005$ & $0.400 \pm 0.005$ & $30.3 \pm 0.04$ & $30.5 \pm 0.04$ \\
\hline $\mathrm{Nd}$ & $1.77 \pm 0.030$ & $1.80 \pm 0.031$ & $1.82 \pm 0.046$ & $114 \pm 0.1$ & $114 \pm 0.1$ \\
\hline $\mathrm{Sm}$ & $0.49 \pm 0.007$ & $0.50 \pm 0.008$ & $0.488 \pm 0.014$ & $18.0 \pm 0.09$ & $18.2 \pm 0.09$ \\
\hline $\mathrm{Eu}$ & $0.598 \pm 0.002$ & $0.591 \pm 0.002$ & $0.583 \pm 0.010$ & $0.314 \pm 0.002$ & $0.322 \pm 0.002$ \\
\hline Gd & $0.601 \pm 0.006$ & $0.612 \pm 0.008$ & $0.590 \pm 0.027$ & $15.9 \pm 0.11$ & $16.3 \pm 0.11$ \\
\hline $\mathrm{Tb}$ & $0.100 \pm 0.005$ & $0.102 \pm 0.003$ & $0.0947 \pm 0.004$ & $1.46 \pm 0.002$ & $1.49 \pm 0.002$ \\
\hline Dy & $0.592 \pm 0.009$ & $0.611 \pm 0.011$ & $0.605 \pm 0.030$ & $7.64 \pm 0.100$ & $7.69 \pm 0.100$ \\
\hline Ho & $0.129 \pm 0.003$ & $0.135 \pm 0.004$ & $0.126 \pm 0.007$ & $1.54 \pm 0.028$ & $1.53 \pm 0.027$ \\
\hline $\mathrm{Er}$ & $0.400 \pm 0.010$ & $0.402 \pm 0.010$ & $0.36 \pm 0.019$ & $4.91 \pm 0.033$ & $4.94 \pm 0.035$ \\
\hline $\mathrm{Tm}$ & $0.061 \pm 0.002$ & $0.064 \pm 0.002$ & $0.0579 \pm 0.003$ & $0.820 \pm 0.018$ & $0.824 \pm 0.018$ \\
\hline $\mathrm{Yb}$ & $0.407 \pm 0.006$ & $0.402 \pm 0.007$ & $0.38 \pm 0.019$ & $5.94 \pm 0.066$ & $5.98 \pm 0.065$ \\
\hline $\mathrm{Lu}$ & $0.063 \pm 0.002$ & $0.066 \pm 0.002$ & $0.0614 \pm 0.004$ & $0.948 \pm 0.010$ & $0.950 \pm 0.009$ \\
\hline
\end{tabular}

*l Samples 1 and 2 were pretreated in duplicate with duplicate columns, and the solutions were measured in five replicates by ICP-MS.

The figures with \pm show the standard deviations of five measurements.

*2Pin and Joannon (1997).

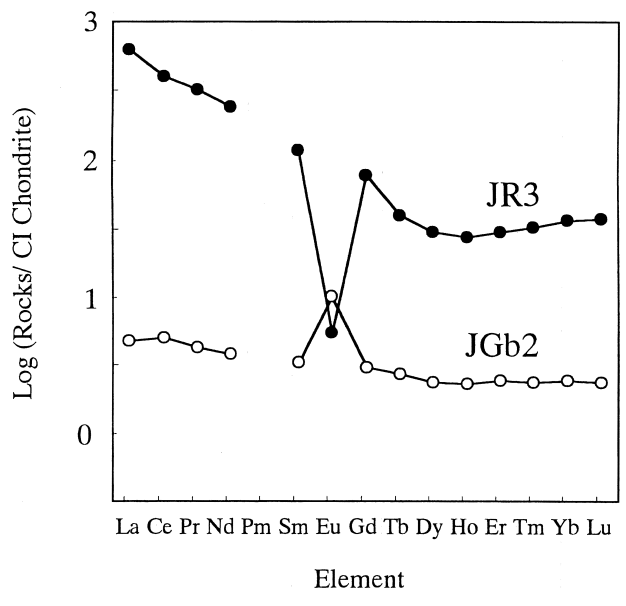

Fig. 2. REE abundances in some GSJ standard rocks normalized to those of CI Chondrite.

data can show some inconsistencies in the data by the irregularities appeared in the normalized patterns. Entirely, the two rock standard samples did exhibit smooth pattern, but large negative Euanomaly in JR3 and large positive Eu-anomaly in JGb2 was shown, respectively.

\section{Conclusions}

The combination of the column separation of REEs from matrix substances with ICP-MS method was found to be a very useful method for the determination of REEs in a wide variety of rocks. Wide range calibration graphs gave the best choice for the optimal determination ranges of elements. The effect of metal oxide species on isobaric isotopes of REEs were found to be favorably corrected for REEs determination by the proposed method. The author recommend the separation of REEs in rock samples from the matrix elements before ICP-MS measurement because of accomplishing more reliable analysis, more reproducible measurement and less damage to mass spectrometer; matrix-eliminated sample throughput showed excellent long-term instrumental stability, which enabled us to apply ICP-MS to the accurate routine analysis for the determination of REEs in rocks. 


\section{REFERENCES}

Abbey, S. (1980) Studies in "standard samples" for use in the general analysis of silicate rocks and minerals. Geostand. Newsl. 4, 163-190.

Anders, E. and Grevesse, N. (1989) Abundances of the elements: Meteoritic and solar. Geochim. Cosmochim. Acta 53, 197-214.

Barrat, J. A., Keller, F. and Amosse, J. (1996) Determination of rare earth elements in sixteen silicate reference samples by ICP-MS after Tm addition and ion exchange separation. Geostand. Newsl. 20, 133-139.

Date, A. R., Cheung, Y. Y. and Stuart, M. E. (1987) The influence of polyatomic ion interferences in analysis by inductively coupled plasma source mass spectrometry (ICP-MS). Spectrochim. Acta 42B, 320.

Doherty, W. (1989) An internal standardization procedure for the determination of yttrium and the rare earth elements in geological materials by inductively coupled plasma-mass spectrometry. Spectrochim. Acta 44B, 263-280.

Govindaraju, K. (1984) 1984 compilation of working values and sample description of 170 international reference samples of mainly silicate rocks and minerals. Special Issue of Geostand. Newsl., 16 pp. plus appendices.

Gray, A. L. (1986) Mass spectrometry with an inductively coupled plasma as an ion source: the influence on ultratrace analysis of background and matrix response. Spectrochim. Acta 41B, 151-167.

Gray, A. L. and Williams, J. G. (1987) System optimisation and the effect on polyatomic, oxide and doubly charged ion response of a commercial inductively coupled plasma mass spectrometry instrument. J. Anal. Atom. Spectrom. 2, 599-606.

Hirata, T., Shimizu, H., Akagi, T., Sawatari, H. and Masuda, A. (1988) Precise determination of rare earth elements in geological standard rocks by inductively coupled plasma source mass spectrometry. Anal. Sci. 4, 637-643.

Horlick, G., Tan, S. T., Vaughan, M. A. and Rose, C. A. (1985) The effect of plasma operating parameters on analyte signals in inductively coupled plasma-mass spectrometry. Spectrochim. Acta 40B, 1555-1572.

Hwang, T.-J. and Jiang, S.-J. (1997) Determination of trace amounts of zinc in water samples by flow injection isotote dilution inductively coupled plasma mass spectrometry. Analyst 122, 233-237.

Imai, N. (1990) Multielement analysis of rocks with the use of geological certified reference material by inductively coupled plasma mass spectrometry. Anal. Sci. 6, 389-395.
Itoh, A., Iwata, K., Ji, S., Yabutani, T., Kimata, C., Sawatari, H. and Haraguchi, H. (1998) Multielement determination of rare earth elements in river water certified reference materials (JAC 0031, JAC 0032) by ICP-MS and ICP-AES with chelating resin preconcentration. Bunseki Kagaku 47, 109-117.

Itoh, A., Hamanaka, T., Rong, W., Ikeda, K., Sawatari, H., Chiba, K. and Haraguchi, H. (1999) Multielement determination of rare earth elements in geochemical samples by liquid chromatography/inductively coupled plasma mass spectrometry. Anal. Sci. 15, 1722.

Jarvis, K. E. and Jarvis, I. (1988) Determination of the rare-earth elements and yttrium in 37 international silicate reference materials by inductively coupled plasma-atomic emission spectrometry. Geostand. Newsl. 12, 1-12.

Lee, K.-H., Oshima, M., Takayanagi, T. and Motomizu, S. (2000) Simultaneous determination of lanthanoids and yttrium in rock reference samples by inductively coupled plasma-mass spectrometry coupled with cation exchange pretreatment. Bull. Chem. Soc. Jpn. 73, 615-622.

Lichte, F. E., Meier, A. L. and Crock, J. G. (1987) Determination of rare-earth elements in geological materials by inductively coupled plasma mass spectrometry. Anal. Chem. 59, 1150-1157.

Longerich, H. P., Fryer, B. J., Strong, D. F. and Kantipuly, C. J. (1987) Effect of operating conditions on the determination of the rare earth elements by inductively coupled plasma-mass spectrometry (ICPMS). Spectrochim. Acta 42B, 75-92.

Panday, V. K., Hoppstock, K., Becker, J. S. and Dietze, H.-J. (1996) Determination of rare earth elements in environmental materials by ICP-MS after liquid-liquid extraction. At. Spectrosc. 17, 98-105.

Pin, C. and Joannon, S. (1997) Low-level analysis of lanthanides in eleven silicate rock reference materials by ICP-MS after group separation using cationexchange chromatography. Geostand. Newsl. 21, 4350 .

Sawatari, H., Toda, T., Saizuka, T., Kimata, C., Itoh, A. and Haraguchi, H. (1995) Multielement determination of rare earth elements in coastal seawater by inductively coupled plasma mass spectrometry after preconcentration using chelating resin. Bull. Chem. Soc. Jpn. 68, 3065-3070.

Sen Gupta, J. G. and Bertrand, N. B. (1995) Direct ICPMS determination of trace and ultratrace elements in geological materials after decomposition in a microwave oven I. Quantitation of $\mathrm{Y}, \mathrm{Th}, \mathrm{U}$ and the lanthanides. Talanta 42, 1595-1607.

Shinotsuka, K., Hidaka, H., Ebihara, M. and Nakahara, 
H. (1996) ICP-MS analysis of geological standard rocks for yttrium, lanthanoids, thorium and uranium. Anal. Sci. 12, 917-922.

Stroh, A., Bea, F. and Montero, P. G. (1995) Ultratracelevel determination of rare earth elements, thorium, and uranium in ultramafic rocks by ICP-MS. At. Spectrosc. 16, 7-11.

Tsuji, H., Fujiwara, S., Chayama, K., Teranishi, K. and Isomura, K. (1998) Determination of rare-earth elements in Arima spring water by ICP-MS with ionexchange separation. Bunseki Kagaku 47, 699-705.

Vaughan, M. A. and Horlick, G. (1986) Oxide, hydroxide, and doubly charged analyte species in inductively coupled plasma/mass spectrometry. Appl. Spectrosc. 40, 434-445.

Vaughan, M. A. and Horlick, G. (1990) Correction procedures for rare earth element analysis in inductively coupled plasma-mass spectrometry. Appl. Spectrosc. 44, 587-593.

Zhang, T.-H., Shan, X.-Q., Liu, R.-X., Tang, H.-X. and Zhang, S.-Z. (1998) Preconcentration of rare earth elements in seawater with poly(acrylaminophosphonic dithiocarbamate) chelating fiber prior to determination by inductively coupled plasma mass spectrometry. Anal. Chem. 70, 3964-3968. 